\title{
The position of the mental foramen in the north and south Indian populations
}

\author{
Naveen Srinivas ${ }^{1}$, Praveenkumar Ramdurg ${ }^{1}$, Surekha R Puranik ${ }^{1}$, Ketki Sali ${ }^{2}$, \\ Pramod Ingaleshwar ${ }^{3}$
}

${ }^{1}$ Department of Oral Medicine and Radiology, PMNM Dental College and Hospital, Bagalkot, ${ }^{2}$ Private practitioner Shivleela Dental Clinic Bagalkot ${ }^{3}$ Department of Oral Pathology, PMNM Dental College and Hospital, Bagalkot

Correspondence: nvns03@gmail.com

Tel.: + 919964140521

Fax.: + 08354221960

Received: 28 December 2016

Accepted: 20 March 2017

Key words: Mental foramen - Indian Populations - Panoramic radiography.

\begin{abstract}
Objective. The aim of the study was to determine and compare the position of the mental foramen MF in the north and south Indian populations using Panoramic radiographs. Materials and methods. A total of 100 Panoramic radiographs were selected from the archives of PMNM Dental College and the Department of Oral Medicine and Radiology, of which 50 radiographs belonged to a north Indian population and 50 radiographs belonged to a local population of Bagalkot Karnataka. The position of the MF was classified into 6 positions depending on the relationship to the mandibular teeth. The distance from the superior border of the MF to the lower border of the mandible was also measured. Results. The most common position of the MF was along the long axis of the second premolar in the north Indian population and in south Indian populations it was found to be between the first and second premolar. Descriptive analysis was used to compare the distance between the superior border of the mental foramen and the lower border of the mandible bilaterally. Conclusion. There was a significant difference in the position of the MF between the north and south Indian populations.
\end{abstract}

\section{Introduction}

The mental foramen (MF) is a funnel-like opening in the lateral surface of the mandible at the terminus of the mental canal (1). The mandibular nerve exits the mental foramen along with the mental vessels, providing both innervation and blood supply to the lower lip, the gingiva on the ipsilateral side anterior to the first molar, and the buccal vestibule (2). The MF is a significant and vital landmark in the mandible during routine clinical and diagnostic procedures, such as mental nerve block and other osteotomy procedures. It is also a very important structure for evaluation of the maturity of the lower jaw, placement of implants, remodelling activity of the bone and, more importantly, the paleoanthropological features of the lower jaw in a range of ethnic groups (3).

Due to its position, it is difficult to evaluate the position of the MF clinically. Radiographically the MF is appreciated as a round or oval radiolucent area in the inferior part of the body of the mandible on both sides (4). Due to the oblique path of the mental canal, it is difficult to identify the MF consistently on intra oral radiography. Panoramic radiographs are the most commonly used extraoral radiographic aids in dentistry since they provide a rapid and wide picture 
of both the mandible and the maxilla. This technique allows the more accurate localization of the MF (5). The location of the MF may change with age. In childhood it is located between the primary canine and the 1st molar, whereas in the edentulous jaw, it is nearer to the upper border of the mandible due to bone resorption. (6). The position of the MF varies not only with age, sex and ethnicity, but even within the same race in different topographic regions, and within the same population in the same geographic location (1, 5, 7-9).

The purpose of the present study was to determine and compare the position of the MF in north and south Indian sub populations, using an orthopantomogram (OPG).

\section{Materials and methods}

The study was conducted at the Department of Oral Medicine and Radiology, Parvatha Gowda Mallanagouda Nadagouda Memorial Dental College and Hospital, from the demographic data and radiographs of patients who had visited the college for various dental treatments. A total of 2648 OPGs were examined between 2013 and 2015, and 100 radiographs were selected, of which 50 radiographs belonged to the north Indian population and 50 radiographs belonged to the local population of Bagalkot Karnataka. All the radiographs were taken using a Kodak $8000 \mathrm{C}$ (tube voltage $60-90 \mathrm{kV}$, tube current $2-15 \mathrm{~mA}$, tube focal spot $0.5 \mathrm{~mm}$, total filtration $>2.5 \mathrm{~mm}$ eq. Al with exposure time of 4-14 seconds). Two oral radiologists were asked to analyse the radiographs, who were blinded about the study. Institutional ethical clearance was obtained. Inclusion criteria: 1. Bilateral presence of a mental foramen which could be clearly identified on the radiograph; 2. Presence of all the teeth in the mandible between the right second and left second molars; 3 . Patients aged $16-45$ years; 4. Absence of crowding of the mandibular premolar and canine area. Exclusion criteria: 1. Patients with periodontal problems such as mobility of the posterior teeth, supraeruption and bone loss; 2. Periapical lesions in the mandible; 3. Patient who are taking/ had undergone orthodontic treatment; 4 . Patients who have undergone maxillofacial surgery of the mandible; 5. Radiographs with impacted or mixed dentition; 6. Poor quality of radiograph. 7. Supra-eruption or pathological migration of mandibular teeth.

The position of the MF on the OPG was classified as per the criteria given by $\mathrm{Al}$ Jasser NM, Nwoku AL (10-12). Position 1: MF

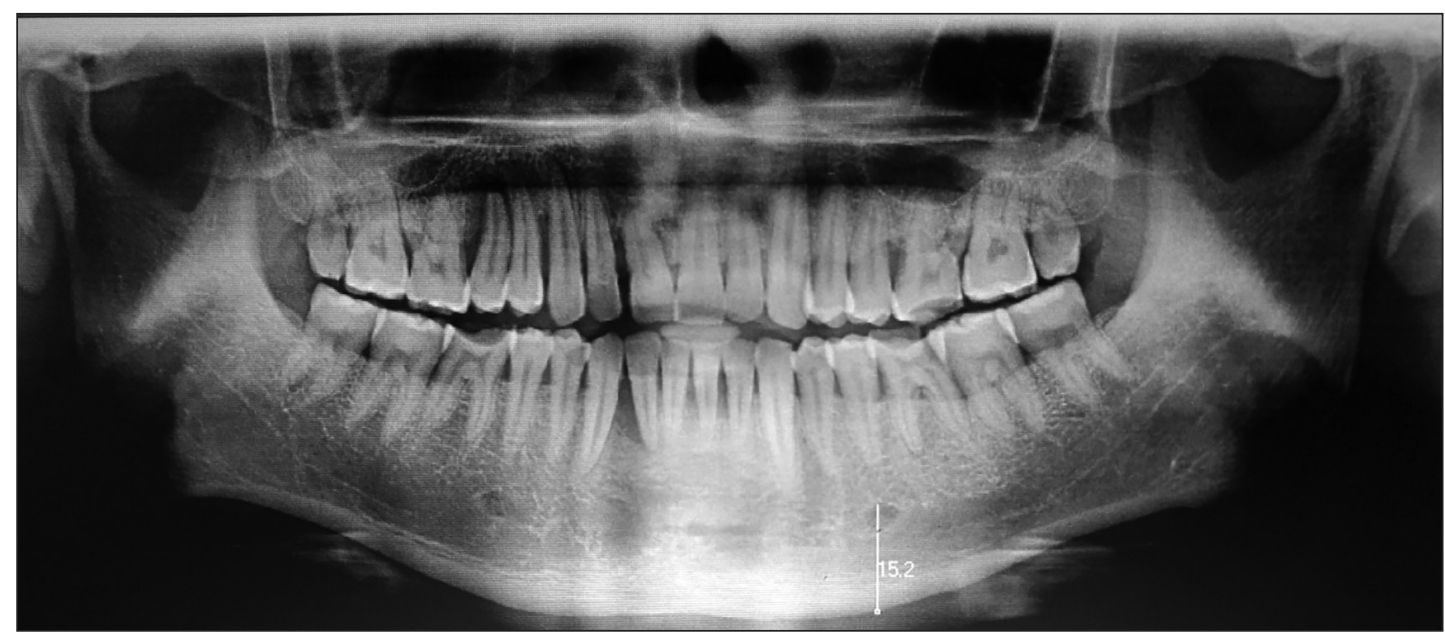

Figure 1 Orthopantomogram showing the distance between the superior border of the mental foramen to the inferior border of the mandible. 
situated anterior to the first premolar tooth; Position 2: MF situated in line with the long axis of the first premolar tooth; Position 3: MF situated between the apices of the first and second premolar teeth; Position 4: MF situated in line with the long axis of the second premolar tooth; Position 5: MF situated between the apices of the second premolar and first molar teeth.; Position 6: MF situated in line with the long what the first molar tooth.

The vertical position of the MF was measured in millimetres with reference to the lower border of the mandible, using Kodak dental imaging software 6.12.11.0, from the superior border of the mental foramen on either side, to the lower border of the mandible (Figure 1).

\section{Statistical analysis}

Descriptive statistics was used to measure the percentages with respect to the position of MF in both north and south Indian populations. An independent $t$ test was done to compare the mean value of the superior border of the mental foramen to the lower border of the mandible in both north and south Indian populations on both the left and right sides of the mandible.

\section{Results}

Table 1 shows the percentages with respect to the position of the MF in both north and south Indian populations. Position 4 was the most common, followed by position 3 , with $58 \%$ and $18 \%$ respectively in the north Indian population. In the south Indian population position 3 was most common, with $62 \%$, followed by position 4 , with $24 \%$.

Table 2 shows the comparison of the mean value of the superior border of the MF to the lower border of the mandible on the left side, giving a mean value of 1.32 and a standard deviation of 2.00 w.r.t with respect to the south Indian population, and a mean value of 1.07 and a standard deviation of 2.64 w.r.t with respect to the north Indian population, which is a highly significant difference, with a $\mathrm{p}$ value of $<0.001$. Similarly, Table 2 gives a mean value of 1.27 with a standard deviation of 2.51 w.r.t with respect to the south Indian population, and a mean value of 1.02 and a standard deviation of 2.55 w.r.t with respect to the north Indian population, which is a highly significant difference with a $p$ value of $<0.001$ on the right side.

Table 3 shows statistical analysis using an independent $t$ test for comparison of mean

Table 1 Position of the mental foramen on Orthopantomograms

\begin{tabular}{|c|c|c|c|c|}
\hline Position of mental foramen & $\begin{array}{l}\text { Cases out of } 50 \\
\text { in north Indian } \\
\text { population (n) }\end{array}$ & $\begin{array}{l}\% \text { of north } \\
\text { Indian } \\
\text { population }\end{array}$ & $\begin{array}{l}\text { Cases out of } 50 \\
\text { in south Indian } \\
\text { population (n) }\end{array}$ & $\begin{array}{l}\% \text { of south } \\
\text { Indian } \\
\text { population }\end{array}$ \\
\hline MF situated anterior to the first premolar tooth & 3 & 6 & 1 & 2 \\
\hline $\begin{array}{l}\text { MF situated in line with the long axis of the first } \\
\text { premolar tooth }\end{array}$ & 8 & 16 & 1 & 2 \\
\hline $\begin{array}{l}\text { MF situated between the apices of the first and second } \\
\text { premolar teeth }\end{array}$ & 9 & 18 & 31 & 62 \\
\hline $\begin{array}{l}\text { MF situated in line with the long axis of the second } \\
\text { premolar tooth }\end{array}$ & 29 & 58 & 12 & 24 \\
\hline $\begin{array}{l}\text { MF situated between the apices of the second premolar } \\
\text { and first molar teeth }\end{array}$ & 0 & 0 & 5 & 10 \\
\hline $\begin{array}{l}\text { MF situated in line with the long axis of the first molar } \\
\text { tooth }\end{array}$ & 1 & 2 & 0 & 0 \\
\hline
\end{tabular}

$\mathrm{MF}=$ Mental foramen 
Table 2 The distance from the superior border of the MF to the lower border of the mandible in north and south Indian populations, on the left and right sides

\begin{tabular}{|c|c|c|c|}
\hline \multirow[b]{2}{*}{ Area } & \multirow{2}{*}{$\begin{array}{l}\text { Radiograph } \\
\text { (n) }\end{array}$} & \multicolumn{2}{|c|}{ Distance $(\mathrm{mm})^{*}$} \\
\hline & & $\begin{array}{l}\text { Left side } \\
(\text { Mean } \pm \text { SD) }\end{array}$ & $\begin{array}{l}\text { Right side } \\
\text { (Mean } \pm \text { SD) }\end{array}$ \\
\hline $\begin{array}{l}\text { South } \\
\text { Indian }\end{array}$ & 50 & $1.32 \pm 2.00^{+}$ & $1.27 \div 2.51^{\dagger}$ \\
\hline $\begin{array}{l}\text { North } \\
\text { Indian }\end{array}$ & 50 & $1.07 \pm 2.64$ & $1.02 \pm 2.55$ \\
\hline
\end{tabular}

*Between the superior border of the mental foramen and the lower border of the mandible.

value of the superior border of the mental foramen to the lower border of the mandible in north and south Indian population on the left side, with Levenes's test for Equality of Variances. A significant difference was seen, with a mean difference of 2.49 and $p$ value of 0.01 .
Table 4 shows analysis using an independent $t$ test for comparison of the mean value of the superior border of the mental foramen to the lower border of the mandible in north and south Indian populations on the right side with Levenes's test for Equality of Variances. A significant difference was seen, with a mean difference of 2.51 and $p$ value of 0.36 .

\section{Discussion}

The present study is in accordance with similar studies conducted in Rajasthan, in the north-eastern states of India (13), Gujurath (14), and Kashmir (15) which are states in the northern part of India. The most common position in the south Indian population was position 3 , situated between the apices of the first and second premolar teeth,

Table 3 Comparison of the mean value of the superior border of the mental foramen to the lower border of the mandible in north and south Indian populations on the left side

\begin{tabular}{|c|c|c|c|c|c|c|c|c|c|}
\hline & \multicolumn{2}{|c|}{$\begin{array}{l}\text { Levene's test for } \\
\text { equality of variances }\end{array}$} & \multicolumn{7}{|c|}{ t-test for equality of means } \\
\hline & \multirow[t]{2}{*}{$\mathrm{F}$} & \multirow[t]{2}{*}{ Sig.* } & \multirow[t]{2}{*}{$\mathrm{t}$} & \multirow[t]{2}{*}{ Df } & \multirow{2}{*}{$\begin{array}{l}\text { Sig. } \\
\text { (2-tailed) }\end{array}$} & \multirow{2}{*}{$\begin{array}{l}\text { Mean } \\
\text { difference }\end{array}$} & \multirow{2}{*}{$\begin{array}{l}\text { Std. error } \\
\text { difference }\end{array}$} & \multicolumn{2}{|c|}{$\begin{array}{l}95 \% \mathrm{Cl}^{+} \text {of the } \\
\text { difference }\end{array}$} \\
\hline & & & & & & & & Lower & Upper \\
\hline LTSL $^{\ddagger}$ & 6.38 & 0.01 & 5.3 & 98 & 0.000 & 2.49 & 0.46 & 1.55 & 3.42 \\
\hline LTSL $^{\S}$ & - & - & 5.3 & 91.3 & 0.000 & 2.49 & 0.46 & 1.55 & 3.42 \\
\hline
\end{tabular}

*Independent Samples Test ( $p$ value); ${ }^{\dagger}$ Confidence Interval; LTSL=Distance from the left side superior border of the mental foramen to the lower border of the mandible ( ${ }^{\ddagger}$ Equal variances assumed;n§Equal variances not assumed).

Table 4 Comparison of the mean value of the superior border of the mental foramen to the lower border of the mandible in north and south Indian populations on the right side.

\begin{tabular}{|c|c|c|c|c|c|c|c|c|c|}
\hline & \multicolumn{2}{|c|}{$\begin{array}{l}\text { Levene's test for } \\
\text { equality of variances }\end{array}$} & \multicolumn{7}{|c|}{ t-test for equality of means } \\
\hline & \multirow[t]{2}{*}{$\mathrm{F}$} & \multirow[t]{2}{*}{ Sig. ${ }^{*}$} & \multirow[t]{2}{*}{$\mathrm{t}$} & \multirow[t]{2}{*}{ Df } & \multirow[t]{2}{*}{ Sig $(2 \text {-tailed })^{*}$} & \multirow{2}{*}{$\begin{array}{l}\text { Mean } \\
\text { difference }\end{array}$} & \multirow{2}{*}{$\begin{array}{l}\text { Std. error } \\
\text { difference }\end{array}$} & \multicolumn{2}{|c|}{$\begin{array}{l}95 \% \mathrm{Cl}^{+} \text {of the } \\
\text { difference }\end{array}$} \\
\hline & & & & & & & & Lower & Upper \\
\hline $\mathrm{RTSL}^{\ddagger}$ & 0.84 & 0.84 & 0.36 & 4.96 & 98 & 0.000 & 2.51 & 0.50 & 1.51 \\
\hline $\mathrm{RTSL}^{\S}$ & - & - & 4.96 & 97.97 & 0.000 & 2.51 & 0.5 & 1.51 & 3.52 \\
\hline
\end{tabular}

*Independent Samples Test ( $p$ value); †Confidence Interval; RTSL=Distance from the right side superior border of mental foramen to the lower border of mandible (‡Equal variances assumed; §Equal variances not assumed). 
seen in $62 \%$ of cases. The results obtained are analogous to the studies performed in the southern states of India $(11,16,17)$. The present study also added another parameter, i.e. the distance between the superior border of the MF and the lower border of the mandible bilaterally. The results showed that there was a significant difference between the measurements, giving a mean value of on 1.27 and 1.02 and a SD of 2.51 and 2.55 for the south and north Indian populations respectively, on the right side. Similarly a mean value of 1.32 and 1.07 and $\mathrm{SD}$ of 2.00 and 2.64 for the south and north Indian populations, respectively, was found on the left side. This indicated that the mental foramen was closer to the lower border of the mandible in the north Indian population.

The reason for the difference in the morphological alterations in the position of the MF may be attributed to the different ethnic origins. Aryans who migrated to India from central Asia constitute the north Indian population while Dravidians constitute the local south Indian population (18). Another reason may be the differences in diet and climate, which influence body height and craniofacial variability (19). It was noted from the results of our study that there is a significant difference in the position of the MF in the two study cohorts. The results may be used as a unique identification landmark in cases of mass disaster, forensics, and anthropological studies. Furthermore, they may be helpful in various dental procedures, such as nerve block, implant placement, and orthognathic surgeries.

\section{Limitations of the study}

The sample size was small considering the duration of the study which was 2 years, due to the smaller inflow of the north Indian population, as our institution is situated in the southern part of India. The other limitation of the study is that the magnification of the OPG was not taken into consideration. Hence a definite conclusion cannot be drawn.

\section{Conclusion}

The most common position of the MF in the south Indian population was between the two mandibular premolars, and in the north Indian population it was below the long axis of the second mandibular premolar, so there was a significant difference in the distance between the superior border of the MF and the lower border of the mandible bilaterally between the two populations.

\section{What is already known on this topic}

The mental foramen is a prominent radiographic landmark in the lower jaw, where the mandibular nerve exits the mandible and supplies the anterior teeth and the soft tissues. There have been various studies conducted by different authors regarding the position of the mental foramen with respect to mandibular pre-molars and molars, along with its location in different populations. However, no comparison of the position of the mental foramen between two different ethnic groups has been attempted before.

\section{What this study adds}

In the present study we attempted to find the relationship between the position of the mental foramen between the north and south Indian populations. We speculated that in the south Indian population the most common position of the mental foramen was between the two mandibular premolars, and in the north Indian population it was below the long axis of the second mandibular premolar. We also added a new parameter, which is the distance between the superior border of the mental foramen and lower border of the mandible, whereby it was calculated that the mental foramen was closer to the lower border in the north Indian population.

Authors' contributions: Conception and design: NS, PR and KS; Acquisition, analysis and interpretation of data: NS and PR; Drafting the article: NS, PR, KS, SRP and PI; Revising it critically for important intellectual content: NS, PR, KS, SRP and PI; Approved final version of the manuscript: NS, PR, KS, SRP and PI.

Conflict of interest: The authors declare that they have no conflict of interest. 


\section{References}

1. Phillips JL, Weller RN, Kulild JC. The mental foramen: 2. Radiographic position in relation to the mandibular second premolar. J Endod. 1992;18(6):271-4.

2. Bavitz JB, Harn SD, Hansen CA, Lang M. An anatomical study of mental neurovascular bundleimplant relationships. Int J Oral Maxillofac Implants. 1993;8(5):563-7.

3. Hasan T. Characteristics of the Mental Foramen in Different Populations. The Internet Journal of Biological Anthropology. 2011;4(2).

4. Moiseiwitsch JR. Position of mental foramen in a North American, White population. Oral Surg Oral Med Oral Pathol Oral Radiol Endod. 1998;85(4):457-60.

5. Phillips JL, Weller RN, Kulild JC. The mental foramen: 3. Size and position on panoramic radiograph. J Endod. 1992;18(8):383-6.

6. Shankland WE. The position of the mental foramen in Asian Indians. J Oral Implantol. 1994;20(2):118-23.

7. Lindh C, Petersson A, Kling B. Measurements of distances related to the mandibular canal in radiographs. Clin Oral implant Res. 1995;6(2):96-103.

8. Ari I, Kafa IM, Basar Z, Kurt MA. The localization and anthropometry of mental foramen on late Byzantine mandibles. Coll Antropol. 2005;29(1):233-6.

9. Santini A, Alayan I. A Comparative anthropometric study of the position of mental foramen in three populations. Br Dent J. 2012;212(4):E7.

10. Ngeow WC, Yuzawati Y. The location of the mental foramen in a selected Malay population. J Oral Sci. 2003;45(3):171-5.
11. Gada SK, Nagda SJ. Assessment of position and bilateral symmetry of occurrence of mental foramen in dentate asian population. J Clin Diagn Res. 2014;8(2):203-5.

12. Al Jasser NM, Nwoku AL. Radiographic study of mental foramen in a selected Saudi population. Dento maxillofac Radiol. 1998;27(6):341-3.

13. Verma P, Bansal N, Khosa R, Verma KG, Sachdev SK, Patwardhan N, et al. Correlation of Radiographic Mental Foramen Position and Occlusion in Three Different Indian Population. West Ind Med J. 2015;64(3):269-74.

14. Agarwal DR, Gupta SB. Morphometric Analysis of Mental Foramen in Human Mandibles of South Gujarat. People's J Sci Res. 2011;4(1):15-8.

15. Ali A, Shah A, Hakim T, Shawl J, Bhat I, Aslam S. Panoramic Radiographic Study of Mental Foramen in Selected Kashmiri Population. Ann Int Med Den Res. 2016;2(4):112-4.

16. Rupesh S, Winnier J, John SA, Joy T, Rao AP, Reddy P. Radiographic Study of Mental Foramen in a Randomly Selected Asian Indian Population on Digital Panoramic Radiographs. J Med Sci. 2011;11(2):90-5.

17. Gupta V, Pitti P, Sholapurkar A. Panoramic radiographic study of mental foramen in selected Dravidians of south Indian population: A hospital based study. J Clin Exp Dent. 2015;7(4):e451-6.

18. Bhasin MK. Indian Anthropology: Racial, Ethnic, Religious and Linguistic Elements in Indian Population [cited 2012 April 4]. Available from: http:// www.upscsuccess.com/sites/default/files/documents/pdf\%2B4.4\%2BNISCAIR-Racial-EthnicRelgious-Linguistic-Groups-India-Text-Revised. pdf.

19. Pandey AK. Cephalo-facial variation among onges. Anthropologist. 2006;8(4):245-9. 